\title{
Prediction of the effectiveness of long term $\beta$ blocker treatment for dilated cardiomyopathy by signal averaged electrocardiography
}

T Yamada, M Fukunami, T Shimonagata, K Kumagai, J Kim, S Sanada, H Ogita, M Hori, N Hoki

\begin{abstract}
s
Objective-To determine whether the effectiveness of long term $\beta$ blocker treatment for idiopathic dilated cardiomyopathy can be predicted by signal averaged electrocardiography (ECG).

Patients-31 patients with dilated cardiomyopathy and without bundle branch block were included in a retrospective study and 16 in a prospective study.

Methods-A signal averaged ECG was recorded before $\beta$ blocker treatment, and three variables were measured from the vector magnitude: QRS duration, root mean square voltage for the last $40 \mathrm{~ms}$ (RMS40), and duration of the terminal low amplitude signals $(<40 \mu \mathrm{V})$ (LAS40). In the retrospective study, these variables were compared among good responders (showing $\geqslant 0.10$ increase in ejection fraction 12 months after start of $\beta$ blocker treatment) and poor responders without such improvement. The validity of the signal averaged ECG criteria for prediction of the response to $\beta$ blocker treatment was examined in the prospective study.
\end{abstract}

Results-In the retrospective study, good responders $(n=16)$ had a shorter QRS duration (mean (SD): 122.9 (11) $v 138$ (14.4) $\mathrm{ms}, \mathrm{p}<0.005)$ and LAS40 (33.1 (8.9) $v 42.5(7.8) \mathrm{ms}, \mathrm{p}<0.005)$, and a higher RMS40 (31.6 (16.3) $v 19.0(10.3) \mu \mathrm{V}$, $p<0.02)$ than poor responders $(n=15)$. Signal averaged ECG criteria for good response were defined as two or more of the following: QRS duration $<130 \mathrm{~ms}$, RMS40 > $20 \mu \mathrm{V}$, LAS40 < 40 ms (sensitivity $81 \%$, specificity $73 \%$ ). In the prospective study, six of seven patients who met these criteria showed a good response to the $\beta$ blocker treatment, while eight of nine who did not showed a poor response $\left(\chi^{2}=6.1, p<0.02\right)$. The signal averaged ECG criteria gave a sensitivity of $86 \%$ and a specificity of $89 \%$ for predicting the effectiveness of $\boldsymbol{\beta}$ blocker treatment.

Conclusions-A signal averaged ECG might be useful in predicting the effectiveness of $\beta$ blocker treatment for dilated cardiomyopathy.

(Heart 1998;79:256-261)

Keywords: signal averaged ECG; $\beta$ blockers; dilated cardiomyopathy
A signal averaged electrocardiogram (ECG) offers a useful approach for identifying patients at risk of ventricular tachycardias ${ }^{1-4}$ and sudden death, ${ }^{2}$ after myocardial infarction. It has been reported recently that abnormal signal averaged ECG findings in patients with idiopathic dilated cardiomyopathy can predict the likelihood of ventricular arrhythmias ${ }^{5-7}$ and an adverse prognosis. ${ }^{8-10}$ Signal averaged ECGs have also been used for detecting heart transplant rejection ${ }^{11}{ }^{12}$ and identifying patients with a poor prognosis in acute myocarditis. ${ }^{13}$ We and other investigators ${ }^{14-16}$ have reported that the signal averaged ECG might be useful for the estimation of the extent of myocardial fibrosis in dilated cardiomyopathy.

Long term $\beta$ blocker treatment has been shown to be useful in the treatment of congestive heart failure caused by idiopathic dilated cardiomyopathy. ${ }^{17-26}$ It has been shown that long term $\beta$ blocker treatment improves cardiac function, ${ }^{19-21}$ relieves associated heart failure symptoms, ${ }^{17}{ }^{18}$ and prolongs survival. ${ }^{22-26}$ However, there is a subgroup of patients with dilated cardiomyopathy who do not respond to $\beta$ blockers. ${ }^{20}{ }^{23} 27$ In an endomyocardial biopsy study, we previously reported that patients with lesser degrees of myocardial fibrosis were likely to respond to $\beta$ blocker treatment. ${ }^{27}$ Unfortunately, it is not feasible to perform a biopsy in all patients before treatment is started. Also, an inherent limitation of the biopsy study was the variability in myocardial fibrosis among different samples. ${ }^{28}$

The purpose of our present study was to determine whether the efficacy of long term $\beta$ blocker treatment in patients with dilated cardiomyopathy could be predicted by using a signal averaged ECG.

\section{Methods}

PATIENT SELECTION AND STUDY DESIGN

The study was in two parts: (1) a retrospective survey of data from routine signal averaged ECG recordings made in 31 consecutive patients without bundle branch block at diagnosis of idiopathic dilated cardiomyopathy; at the time of the survey the patients had completed a year of $\beta$ blocker treatment ${ }^{29}$; (2) a prospective survey of another 16 consecutive patients, also without bundle branch block. All the 47 patients with dilated cardiomyopathy had experienced at least one episode of decompensated heart failure.

Dilated cardiomyopathy was diagnosed by echocardiography, coronary angiography, and endomyocardial biopsy, according to the crite-
Accepted for publication 13 November 1997 
ria proposed by the WHO/ISFC task force. ${ }^{30}$ Patients were considered to have dilated cardiomyopathy if the left ventricular ejection fraction, assessed by echocardiography, was less than 0.55 and the left ventricular end diastolic dimension was greater than $55 \mathrm{~mm}$. Mean (SD) ejection fraction in all 47 study patients was $0.406(0.071)$ (range 0.25 to 0.54 ) and the mean left ventricular end diastolic dimension was $64.1(6.6) \mathrm{mm}$ (range 56 to $81)$. No patients had coronary artery disease $(>25 \%$ diameter reduction of a major coronary vessel). Of the 47 study patients, 15 had minor arteriosclerosis with $\leqslant 25 \%$ lumen stenosis of a coronary artery. In all patients, acute or chronic myocarditis was excluded by the findings at endomyocardial biopsy. Other causes of cardiomyopathy were also excluded. The mean age of the study patients was 57 years (range 21 to 77 ). There were 34 men and 13 women. The average New York Heart Association functional classification was 2.6 (0.6), with $42 \%$ of patients in class II, $56 \%$ in class III, and $2 \%$ in class IV congestive heart failure. Five patients had a history of sustained ventricular tachycardia.

Each patient gave informed consent to participate in this study, which was approved by the Osaka prefectural review committee.

MEASUREMENTS BEFORE ADMINISTRATION OF A $\beta$ BLOCKING AGENT

Before the administration of a $\beta$ blocking agent, all patients underwent echocardiography, cardiac catheterisation, and signal averaged ECG.

\section{Echocardiography}

Cross sectional echocardiography was performed with a Toshiba SSH-160A recorder equipped with 2.5 or $3.75 \mathrm{MHz}$ transducer (Toshiba Co, Tokyo, Japan). The standard technique $^{31}$ was employed for sizing the left ventricle. Left ventricular dimensions were measured at end diastole on the $R$ wave of the electrocardiogram derived QRS complex and at end systole just below the level of mitral leaflets through the standard left parasternal window. The transducer position was aided by cross sectional echocardiographic analysis. Left ventricular ejection fraction was calculated by the method of Gibson. ${ }^{32}$

\section{Cardiac catheterisation}

A Swan-Ganz thermodilution catheter was introduced through the right subclavian vein and positioned in the pulmonary artery. Heart rate, systemic blood pressure, and pulmonary wedge pressure were measured. Cardiac output was determined by the thermodilution technique.

\section{Signal averaged ECG}

Only one patient had received antiarrhythmic drugs for more than one week before undergoing the signal averaged ECG. This patient, in the prospective study, was receiving amiodarone $(100 \mathrm{mg} /$ day $)$ for incessant sustained ventricular tachycardia. In an electrically shielded room, which minimised noise, signal averaged
ECGs were recorded from a modified X, Y, and $Z$ lead system by means of the VCM-3000 (Fukuda Denshi, Tokyo, Japan). The five electrodes were located on right and left shoulders, iliac crests, and at the V1 position. The X lead was between the right and left shoulders. The aVF lead from these electrodes was used as the Y lead. The precordial V1 lead was used as the $\mathrm{Z}$ lead.

The gain of the amplifier was 1000, and the noise input was less than $0.6 \mu \mathrm{V}$. The signal from each lead was amplified and passed through a $300 \mathrm{~Hz}$ low pass filter (slope 12 $\mathrm{dB}$ /octave) and a $40 \mathrm{~Hz}$ high pass filter (slope $18 \mathrm{~dB} /$ octave), and then was converted from analogue to digital data to a 12 bit accuracy at a sampling rate of $1 \mathrm{kHz}$. The three filtered signals were combined into a vector magnitude $\left(\mathrm{X}^{2}+\mathrm{Y}^{2}+\mathrm{Z}^{2}\right)^{1 / 2}$. After elimination of ectopic beats and gross noise by a template recognition program, more than 200 beats were averaged until the noise level (root mean square value) was reduced to less than $0.5 \mu \mathrm{V}$. The end of the filtered QRS complex was automatically determined by a computer algorithm.

The following variables were measured in the vector magnitude by the technical assistants who had no knowledge of clinical data: (1) the duration of filtered QRS complex (QRS duration), (2) the root mean square voltage for the last $40 \mathrm{~ms}$ of filtered QRS complex (RMS40), and (3) the duration of low amplitude signals $<40 \mu \mathrm{V}$ in the terminal portion of filtered QRS complex (LAS40).

DRUG PROTOCOL

Metoprolol was given at an initial dose of 5 to $10 \mathrm{mg} /$ day during the stable stage of the disease after conventional treatment with digitalis and diuretic drugs or angiotensin converting enzyme inhibitors for at least one month. The dose was increased in stepwise increments by 5 to $20 \mathrm{mg}$ /day over an interval of two to four weeks, with careful observation for deterioration of heart failure, up to the final therapeutic dose of $60 \mathrm{mg} /$ day, unless severe hypotension ( $<80 \mathrm{~mm} \mathrm{Hg}$ ), bradycardia (< 40 beats $/ \mathrm{min}$ ), or any signs of clinical decompensation appeared. During the follow up period after the initial signal averaged ECG, there was no change in any of the concomitantly given drugs, including angiotensin converting enzyme inhibitors, and no calcium channel antagonists were given.

EVALUATION OF THE EFFECTIVENESS OF LONG TERM $\beta$ BLOCKER TREATMENT

The effectiveness of long term $\beta$ blocker treatment was assessed again by echocardiography 12 months after the administration of metoprolol, because improvement has been shown in previous studies to be a slow process which may take from three to 12 months. ${ }^{20}{ }^{21}$ According to the degree of improvement in the left ventricular ejection fraction, ${ }^{27}$ the patients were classified into two groups: good responders, with an increase in ejection fraction of $\geqslant 0.10$, and poor responders without such improvement. Ejection fraction was determined without knowledge of the findings of the signal 
Table 1 Baseline data at entry of retrospective study from good and poor responders to long term $\beta$ blocker treatment

\begin{tabular}{lclll}
\hline & \multicolumn{2}{c}{$\begin{array}{c}\text { Good responders } \\
(n=16)\end{array}$} & \multicolumn{3}{c}{$\begin{array}{c}\text { Poor responders } \\
(n=15)\end{array}$} \\
\hline Age (years) & 59 & $(11)$ & 55 & $(10)$ \\
Sex (male/female) & $11 / 5$ & & $11 / 4$ & \\
NYHA functional & & & & \\
$\quad$ class & 2.6 & $(0.5)$ & 2.5 & $(0.6)$ \\
LVDd (mm) & 62.5 & $(5.6)$ & 65.7 & $(7.8)$ \\
LVDs (mm) & 52.8 & $(6.0)$ & 55 & $(8.2)$ \\
LVEF (\%) & 41.1 & $(6.4)$ & 40.9 & $(5.8)$ \\
Heart rate (beats/min) & 87 & $(18)$ & 83 & $(16)$ \\
SBP (mm Hg) & 146 & $(17)$ & 139 & $(25)$ \\
DBP (mm Hg) & 81 & $(13)$ & 86 & $(20)$ \\
PCWP (mm Hg) & 12 & $(6)$ & 13 & $(8)$ \\
CI (1/min/m $\left.{ }^{2}\right)$ & 2.35 & $(0.72)$ & $2.69(0.66)$ \\
Atrial fibrillation & 4 & $(25 \%)$ & 4 & $(27 \%)$ \\
Sustained VT & 0 & $(0 \%)$ & 3 & $(20 \%)$ \\
\hline
\end{tabular}

$\mathrm{p}$, not significant for all data. Data are means (SD) or number of patients.

CI, cardiac index; DBP, systemic diastolic blood pressure; LVDd, left ventricular end diastolic dimension; LVDs, left ventricular end systolic dimension; LVEF, left ventricular ejection fraction; NYHA, New York Heart Association; PCWP, pulmonary capillary wedge pressure; SBP, systemic systolic blood pressure; VT, ventricular tachycardia.

averaged ECG. The interobserver and intraobserver variability in measurements of the ejection fraction-obtained by two independent observers-were $0.033(0.02)(n=25)$ and $0.03(0.019)(\mathrm{n}=42)$, respectively.

\section{STATISTICAL ANALYSIS}

Results are expressed as mean (SD). The Student's $t$ test was used for unpaired data (comparisons of between good and poor responders). A two factor repeated measures analysis of variance was used for paired data (comparison of echocardiographic data between before and 12 months after $\beta$ blocker treatment). The relation between the response to long term $\beta$ blocker treatment and the findings in the baseline signal averaged ECGs was examined with a $\chi^{2}$ test. A $p$ value $<0.05$ was considered significant.

\section{Results}

COMPARISON OF BASELINE DATA IN GOOD AND POOR RESPONDERS

These are shown in table 1 . No patients showed deterioration of congestive heart failure because they received metoprolol. Sixteen patients had good response to the $\beta$ blocker treatment, while the remaining 15 patients had a poor response. There were no significant differences between good and poor responders at entry in age, gender, functional class, or haemodynamic variables (heart rate, systemic blood pressure, pulmonary capillary wedge pressure, cardiac index, left ventricular end diastolic and end systolic dimensions, and ejection fraction); neither were there any significant differences in the proportion of patients with a history of sustained ventricular tachycardia or atrial fibrillation. There was also no difference in the proportion of patients taking angiotensin converting enzyme inhibitors between the two groups ( $53 \%$ v 50\%).

RESPONSE TO LONG TERM $\beta$ BLOCKER

TREATMENT IN THE RETROSPECTIVE STUDY

In good responders, left ventricular end diastolic dimension (62.6 (5.6) to $57.8(4.7) \mathrm{mm}$, $\mathrm{p}<0.001)$ and end systolic dimension $(52.8$ (6.0) to 43.1 (5.7) $\mathrm{mm}, \mathrm{p}<0.001)$ decreased, while ejection fraction markedly increased (0.411 (0.064) to 0.558 (0.074), p < 0.001). Conversely, in poor responders there were no significant changes in left ventricular end diastolic dimension (65.7 (7.8) to 64.1 (8.4) $\mathrm{mm}$ ), end systolic dimension (55 (8.2) to $53.6(8.3) \mathrm{mm})$, or ejection fraction (0.409 $(0.058)$ to $0.428(0.063))$. There was no significant difference in the final dose of metoprolol between good and poor responders (48 (17) $v 47$ (16) $\mathrm{mg} /$ day).

COMPARISON OF VARIABLES OF THE SIGNAL AVERAGED ECGS IN GOOD AND POOR RESPONDERS Figure 1 shows a comparison of the signal averaged ECG variables between good and poor responders. QRS duration (122.9 (11) v 138 (14.4) ms, p < 0.005) and LAS40 (33.1 (8.9) $v 42.5(7.8) \mathrm{ms}, \mathrm{p}<0.005)$ were shorter and RMS40 greater (31.6 (16.3) $v 19.0$ (10.3) $\mu \mathrm{V}, \mathrm{p}<0.02)$ in good than in poor responders. On the other hand, there was no significant difference in QRS duration measured from the standard ECG between the two groups (90 (12) v 98 (13) ms, $\mathrm{p}=0.12$ ).
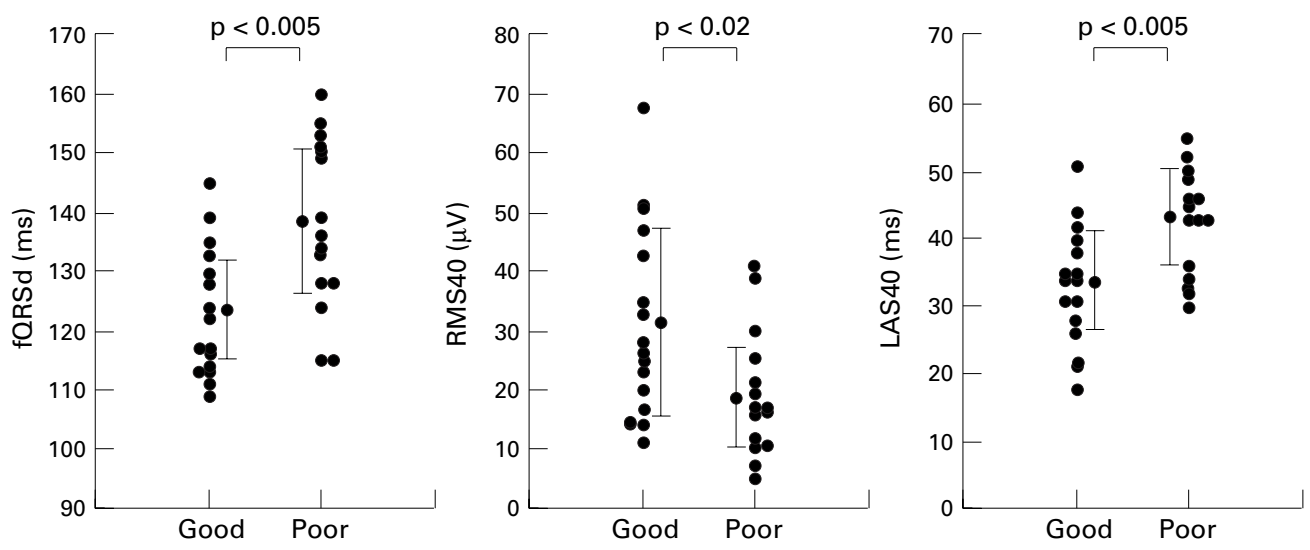

Figure 1 Comparisons of the variables in the signal averaged electrocardiograms between good and poor responders to long term $\beta$ blocker treatment for dilated cardiomyopathy. $f Q R S d$, duration of filtered $Q R S$ complex; RMS40, root mean square voltage of terminal $40 \mathrm{~ms}$ of filtered QRS complex; LAS40, duration of low amplitude signals $<40 \mu \mathrm{V}$. QRS duration and $L A S 40$ were significantly shorter and RMS40 was greater in good than in poor responders. 

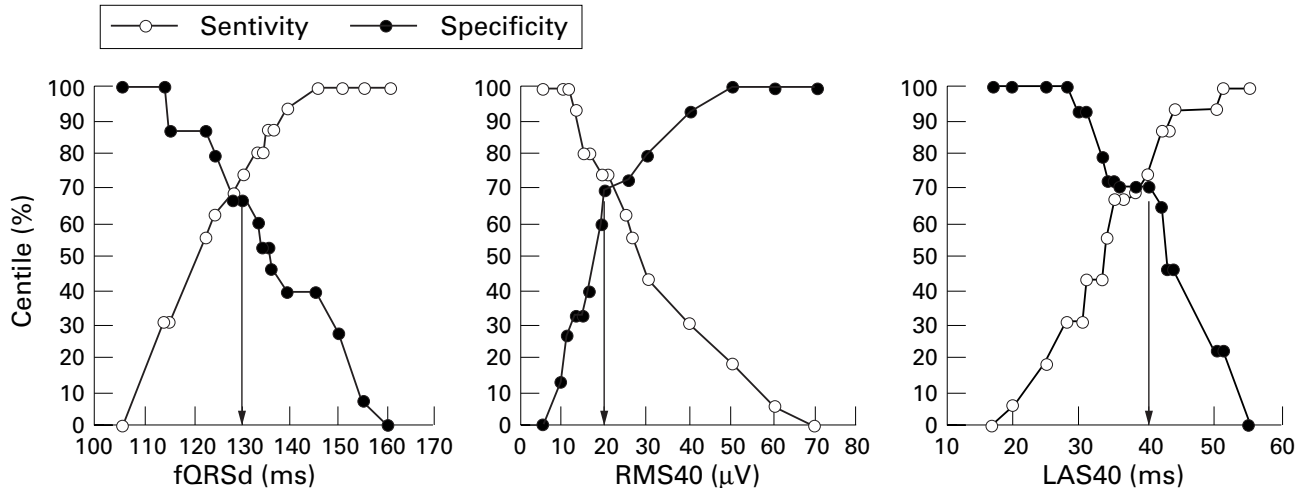

Figure 2 Receiver operating characteristic curves of the variables in the signal averaged ECG for the prediction of the effectiveness to long term $\beta$ blocker treatment for dilated cardiomyopathy. $f Q R S d$, duration of filtered $Q R S$ complex; $R M S 40$, root mean square voltage of terminal $40 \mathrm{~ms}$ of filtered QRS complex; LAS40, duration of terminal low amplitude signals $<40 \mu \mathrm{V}$. Filled and empty circles indicate the sensitivity and specificity, respectively. The cut off levels of the variables in the signal averaged ECG are shown with arrows.

PREDICTION OF THE RESPONSE TO LONG TERM $\beta$ BLOCKER TREATMENT BY USE OF SIGNAL AVERAGED ECG

We determined the cut off values of the variables in the signal averaged ECG that predicted the response to long term $\beta$ blocker treatment by plotting the receiver operating characteristic curve shown in fig 2 . The signal averaged ECG criteria for predicting good response to long term $\beta$ blocker treatment by patients with dilated cardiomyopathy were defined as two or more of the following: QRS duration < $130 \mathrm{~ms}$, LAS40 < $40 \mathrm{~ms}$, RMS40 $>20 \mu \mathrm{V}$. Thirteen of 16 good responders met these criteria and 11 of 15 did not. A significant relation was observed between the criteria of signal averaged ECGs and the effectiveness of long term $\beta$ blockade $\left(\chi^{2}=7.2, \mathrm{p}<0.01\right.$; sensitivity $81 \%$, specificity $77 \%$ ).

PROSPECTIVE STUDY

Seven of 16 patients met the signal averaged ECG criteria for good response, and the remaining nine patients did not. Table 2 gives a comparison of baseline data between the two groups. There were no significant differences at entry in age, gender, functional class, or haemodynamic variables (left ventricular end diastolic and end systolic dimensions and ejection fraction). There were also no differences in
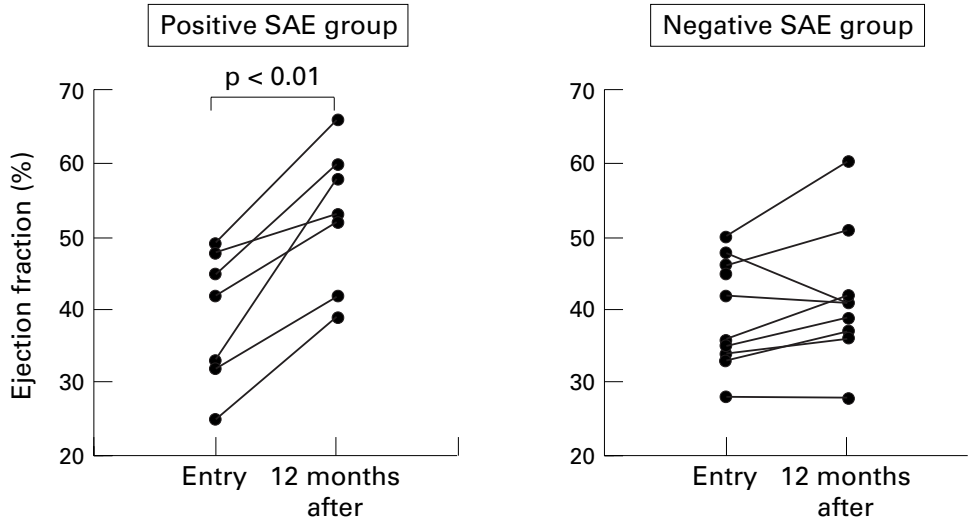

Figure 3 Changes in ejection fraction after long term $\beta$ blocker treatment in 16 prospectively studied patients who either met or did not meet the signal averaged ECG (SAE) criteria for good response. Note that the ejection fraction increased significantly after $\beta$ blocker treatment in patients who met the signal averaged ECG criteria, while there was no significant change in patients who did not meet the criteria.
Table 2 Baseline data at entry to prospective study for patients with positive and negative signal averaged ECG ( $S A E)$ criteria

\begin{tabular}{lcl}
\hline & $\begin{array}{l}\text { Positive SAE } \\
(n=7)\end{array}$ & $\begin{array}{l}\text { Negative SAE } \\
(n=9)\end{array}$ \\
\hline Age (years) & $57 \quad(18)$ & $58 \quad(17)$ \\
Sex (male/female) & $6 / 1$ & $6 / 3$ \\
NYHA functional class & $2.5(0.5)$ & $2.6(0.4)$ \\
LVDd (mm) & $62.2(8.1)$ & $64.5(5.2)$ \\
LVDs (mm) & $52(11)$ & $54(7)$ \\
LVEF (\%) & $38.7(9.6)$ & $39.7(8.6)$ \\
\hline
\end{tabular}

$\mathrm{p}$, not significant for all data. Data are means (SD) or number of patients.

LVDd, left ventricular end diastolic dimension; LVDs, left ventricular end systolic dimension; LVEF, left ventricular ejection fraction; NYHA, New York Heart Association.

the final dose of metoprolol (43 (12) $v 48$ (18) $\mathrm{mg} /$ day) or in the percentage of patients taking angiotensin converting enzyme inhibitors $(86 \% v 85 \%)$ or amiodarone $(0 \% v 11 \%)$ between the two groups. Figure 3 shows the change in ejection fraction after long term $\beta$ blocker treatment. The ejection fraction increased in patients who met the criteria for good response $(0.387$ (0.096) to 0.541 (0.11), $\mathrm{p}<0.01)$, while there was no significant change in patients who did not meet the criteria $(0.397(0.086)$ to $0.423(0.107))$. Thus six of seven patients who met the criteria showed a good response to $\beta$ blocker treatment, while eight of nine patients who did not meet the criteria showed a poor response. A significant relation was observed between the signal averaged ECG criteria and the efficacy of $\beta$ blocker treatment $\left(\chi^{2}=6.1, \mathrm{p}<0.02\right)$. The signal averaged ECG criteria had a sensitivity of $86 \%$, a specificity of $89 \%$, and a predictive accuracy of $88 \%$ for the predicting efficacy of long term $\beta$ blocker treatment.

\section{Discussion}

It has been reported that a subgroup of patients with dilated cardiomyopathy respond dramatically to long term $\beta$ blocker treatment, with symptomatic and functional improvement, ${ }^{17-21}$ and prolonged life. ${ }^{22-26}$ Therefore, it is important to identify the characteristics that allow us to distinguish those patients who will benefit from long term $\beta$ blockade from those who will not. Our study showed that long term $\beta$ blocker treatment is likely to be more effective in 
patients whose signal averaged ECGs have shorter duration filtered QRS complex and terminal low amplitude signals, and a higher voltage for the last $40 \mathrm{~ms}$. These results suggest that the signal averaged ECG may be useful in predicting the efficacy of long term $\beta$ blocker treatment for dilated cardiomyopathy.

RELATION BETWEEN SIGNAL AVERAGED ECG AND THE EFFICACY OF LONG TERM $\beta$ BLOCKER TREATMENT

One possible explanation for an association between the results of signal averaged ECGs and the efficacy of $\beta$ blocker treatment may lie in the amount of endomyocardial fibrosis in hearts affected by dilated cardiomyopathy. Abnormal findings in signal averaged ECGs have been shown to be associated with the presence of diffusely increased interstitial fibrosis. ${ }^{14}{ }^{15}$ We previously reported that patients with more myocardial fibrosis had a longer duration of the filtered QRS complex and terminal low amplitude signals - and lower voltages for the terminal portion-than those with less fibrosis. ${ }^{15}$ Thus patients with a normal signal averaged ECG are likely to have less myocardial fibrosis, and this is thought to be important in predicting the value of long term $\beta$ blocker treatment for dilated cardiomyopathy. ${ }^{27}$ It is reasonable to suppose that patients with more residual non-fibrotic tissue would respond more favourably to this treatment.

COMPARISON WITH PREVIOUS STUDIES

In our present study, haemodynamic variables such as heart rate, cardiac index, pulmonary capillary wedge pressure, left ventricular dimension, and left ventricular ejection fraction were unable to predict improvement with long term $\beta$ blocker treatment. These data suggest that patients with poor haemodynamic status should not necessarily be excluded from the long term $\beta$ blockade. Some investigators have reported that the most favourable response to $\beta$ blocker treatment occurs in patients with the highest baseline heart rate. ${ }^{17}{ }^{18}{ }^{33}$ This result is inconsistent with our results, but the difference could be due to the selection of patients (ischaemic or non-ischaemic in origin). In another recent report, baseline heart rate was not related to changes in left ventricular ejection fraction after $\beta$ blocker treatment in patients with non-ischaemic dilated cardiomyopathy. ${ }^{34}$

It was recently reported that the higher the peak systolic pressure before $\beta$ blocker treatment, the greater the improvement in left ventricular ejection fraction. ${ }^{34}$ Although there was no significant difference in systolic blood pressure at baseline between good and poor responders in this retrospective study, systolic blood pressure was significantly but minimally higher in good than in poor responders, at 145 (14) v 133 (26) $\mathrm{mm} \mathrm{Hg}(\mathrm{p}=0.04)$ in all study patients. These results are consistent with our histological study of endomyocardial biopsies, ${ }^{27}$ which showed that patients with the least fibrosis (that is, with the most residual viable myocardial cells) responded best to treatment.

LIMITATIONS

Patients with bundle branch block were not included in our study because time domain analysis of signal averaged ECGs was performed. It was reported recently that abnormalities of signal averaged ECGs using spectral turbulence analysis predicted the development of progressive heart failure in patients with dilated cardiomyopathy, despite of the presence of bundle branch block. ${ }^{9}$ Further study by frequency analysis will be needed in such patients.

It has been reported that the filtered QRS duration is longer in males than in females, so sex dependent normal limits for the signal averaged ECG were recommended for ventricular late potentials. ${ }^{35}$ Neither in good nor in poor responders in our study were there significant differences in the filtered QRS duration between male and female patients (good responders, 17 males, nine females: $124.8(10.2) v 124.1$ (14.9) ms, respectively; poor responders, 17 males, four females: 136.8 (10.4) v 134 (23.9) $\mathrm{ms}$, respectively); we therefore used sex independent criteria for predicting the efficacy of $\beta$ blocker treatment. However, since the sample size of the female patients was small, it needs to be clarified whether this variable is truly independent of sex.

Although this prospective study showed that there was a significant relation between the efficacy of long term $\beta$ blocker treatment and the signal averaged ECG findings, the sample size was small. Therefore, the validity of the signal averaged ECG criteria need to be verified in a larger prospective trial.

CONCLUSION

This study showed that the signal averaged ECG may be useful in predicting the efficacy of long term $\beta$ blocker treatment in patients with dilated cardiomyopathy.

We thank S Ishida and H Maekawa for technical assistance.

1 Simson MB. Use of signals in the terminal QRS complex to dentify patients with ventricular tachycardia after myocardial infarction. Circulation 1981;64:235-42.

2 Gomes JA, Winters SL, Stewart D, et al. A new noninvasive index to predict sustained ventricular tachycardia and sudindex to predict sustained ventricular tachycardia and sudden death in the first year myocardial infarction based on signal averaged electrocardiogram, radionuclide ejection fraction

3 Cain ME, Ambos HD, Marham J, et al. Diagnostic implication of spectral and temporal analysis of the entire cardiac cycle in patients with ventricular tachycardia. Circulation 991;83:1637-48.

4 Odemuyiwa O, Malik M, Poloniecki J, et al. Frequency versus time domain analysis of signal averaged electrocardiogram. III. Stratification of postinfarction patients for arrhythmic events. F Am Coll Cardiol 1992;20:144-50

5 Poll DS, Marchlinski FE, Falcone RA, et al. Abnormal signal averaged electrocardiograms in patients with nonischemic congestive cardiomyopathy: relationship to sustained ventricular tachycardia. Circulation 1985;72:130813.

6 Denereaz D, Zimmermann M, Adamec R. Significance of ventricular late potentials in nonischemic dilated cardiomyopathy. Eur Heart f 1992;13:895-901.

7 Turitto G, Ahuja RK, Caref EB, et al. Risk stratification for arrhythmic events in patients with nonischemic dilated cardiomyopathy and nonsustained ventricular tachycardia: role of programmed ventricular stimulation and the signalelectrocardiogram. $\mathcal{F}$ Am Coll Cardiol 1994;24:1523-8. 
8 Mancini DM, Wong KL, Simson MB. Prognostic value of an abnormal signal averaged electrocardiogram in patients with non-ischemic congestive cardiomyopathy. Circulation 1993;87:1083-92.

9 Yi G, Keeling PJ, Goldman JKH, et al. Prognostic significance of spectral turbulence analysis of the signal averaged electrocardiogram in patients with idiopathic dilated cardiomyopathy. Am f Cardiol 1995;75:494-7.

10 Bloomfield DM, Hickey K, Sciacca RR, et al. Abnormal signal averaged electrocardiogram predicts mortality in patients with non-ischemic cardiomyopathy and severe
congestive heart failure [abstract]. $\mathcal{F}$ Am Coll Cardiol 1995; (special issue): $215 \mathrm{~A}$

11 Haberl R, Weber M, Reichenspurner $\mathrm{H}$, et al. Frequency analysis of the surface electrogram for recognition of acute rejection after orthotopic cardiac transplantation in man. Circulation 1987;76:101-8.

12 Lacroix D, Kacet S, Savard P, et al. Signal-averaged electrocardiography and detection of heart transplant rejection: comparison of time and frequency domain analyses. $\mathcal{F} \mathrm{Am}$ Coll Cardiol 1992;19:553-8.

13 Mestre JL, Madrid AH, Moro C. Signal-averaged electrocardiography in patients with acute myocarditis. Int $\mathcal{F}$ Car-

14 Schumacher B, Tebbenjohanns J, Korte T, et al. Do abnormal signal averaged electrocardiographic findings in dilated cardiomyopathy represent histological alterations? [abstract]. Circulation 1995;92:I-408.

15 Yamada T, Fukunami M, Ohmori M, et al. New approach to the estimation of the extent of myocardial fibrosis in patients with dilated cardiomyopathy: use of signal averaged electrocardiography. Am Heart 7 1993;126:62631.

16 Yamada T, Abe Y, Fukunami M, et al. Anatomical basis of late potentials in patients with dilated cardiomyopathy [abstract]. Circulation 1995;92:I-741.

17 Waagstein F, Hjalmarson A, Vaunauskas E, et al. Effect of chronic beta adrenergic receptor blockade in congestive chronic beta adrenergic receptor blockade in

18 Engeimeier RS, O'Connel JB, Walsh R, et al. Improvement in symptoms and exercise tolerance by metoprolol in patients with dilated cardiomyopathy: a double-blind, randomized,

19 Heilbrunn SM, Shah P, Bristow MR, et al. Increased beta-receptor density and improved hemodynamic response to catecholamine stimulation during long-term metoprolol therapy in heart failure from dilated cardiomyopathy. Circulation 1989;79:483-90.

20 Waagstein F, Caidahl K, Wallentin I, et al. Long-term betablockade in dilated cardiomyopathy: effects of short- and long-term metoprolol treatment followed by withdrawal and readministration of metoprolol. Circulation 1989;80: 551-63.

21 Fukunami M, Hashimura K, Ohmori M, et al. Effectiveness of long-term beta-blocker therapy for dilated cardiomyopathy: echocardiographical follow up. Cardiovasc Drugs Ther 1991;5:463-70.

22 Swedberg K, Hjalmarson A, Waagstein F, et al. Prolongation of survival in congestive cardiomyopathy by beta-receptor blockade. Lancet 1979;i:1374-6.

23 Anderson JL, Joadn RL, Gilbert EM, et al. A randomized trial of low-dose beta-blockade therapy for idiopathic dilated cardiomyopathy. Am $\mathcal{F}$ Cardiol 1985;55:471-5.

24 Waagstein F, Bristow MR, Swedberg K, et al, for the Metoprolol in Dilated Cardiomyopathy (MDC) Trial Study Group. Beneficial effects of metoprolol in idiopathic dilated cardiomyopathy. Lancet 1993;342:1441-6.

25 CIBIS Investigators and Committees. A randomized trial of beta-blockade in heart failure. Circulation 1994;90:176573

26 Oe H, Fukunami M, Ohmori M, et al. Antiarrhythmic effect of long-term beta-blocker therapy for dilated cardiomyopathy on survival rate [abstract]. $\mathcal{F} \mathrm{Am}$ Coll Cardiol 1995; (special issue): $165 \mathrm{~A}$

27 Yamada T, Fukunami $M$, Ohmori $M$, et al. Which subgroup of patients with dilated cardiomyopathy would benefit from long-term beta-blocker therapy? A histological viewpoint. $\mathcal{f}$ Am Coll Cardiol 1993;21:628-33.

28 Mason JW. Endomyocardial biopsy: the balance of success and failure. Circulation 1985;71:185-8.

29 Yamada T, Abe Y, Fukunami M, et al. Could the effectiveness of long term $\beta$-blocker therapy for dilated cardiomyopathy be predicted by signal averaged ECG? [abstract]. Circulation 1995;92:I-73.

30 Report of the WHO/ISFC Task Force on the definition and classification of cardiomyopathies. Br Heart $\mathcal{F}$ 1980;44: $672-3$.

31 Feigenbaum H. Echocardiography, 4th ed. Philadelphia: Lea and Febiger, 1986:50-126.

32 Gibson DG. Estimation of left ventricular size by echocardiography. Br Heart 7 1973;35:128-34.

33 Bennett SK, Fisher ML, Krichten C, et al Ischemic cardiomyopathy treated with metoprolol: baseline heart rate predicts likelihood of increased ejection fraction [abstract]. Circulation 1993;88:I-105.

34 Eichhorn EJ, Heesch CM, Risser RC, et al. Predictors of systolic and diastolic improvement in patients with dilated cardiomyopathy treated with metoprolol. $f \mathrm{Am}$ Coll Cardiol 1995;25:154-62.

35 Yang TF, Macfarlene PW. New sex dependent normal limits of the signal averaged electrocardiogram. Br Heart $\mathcal{F} 1994$; 72:197-200. 